\title{
REAL-TIME DIAGNOSIS OF THREE-PHASE INDUCTION MACHINE USING ARDUINO-UNO CARD BASED ON PARK'S CIRCLE METHOD
}

\author{
Mohamed BOUDIAF ${ }^{1}$, Lakhmissi CHERROUN ${ }^{2}$, Maroua BENBRIKA $^{3}$ \\ Applied Automation and Industrial Diagnostics Laboratory, Faculty of Sciences and Technology, Ziane Achour \\ University, Djelfa 17000 DZ, Algeria, ${ }^{1}$ boudhiaf_mohamed@yahoo.fr, ${ }^{2}$ cherroun_lakh@yahoo.fr, \\ 3. menbrika1009@gmail.com
}

\begin{abstract}
The main role of diagnosis is the real-time detection of the different types of faults on the physical system. Induction motors are nowadays used more frequently than any other electric motor in various kinds of electric drives. Incipient fault diagnosis is very important because if the fault is undetected, small motor failure can lead to serious motor failure. The objective of this work is the study and the realization of a diagnosis based on signal processing by the Park method of a wound rotor induction machine (in real-time). We have chosen for the realization of this diagnostic strategy the Arduino-UNO board and the ACS-720 current sensor as a signal acquisition system. The results obtained in practice show that this method of diagnosis is a very powerful and very sensitive technique for signaling and identifying the different types of faults and achieving the desired objectives.
\end{abstract}

Keywords: Circle of Park method, Induction Machine, Arduino-Uno microcontroller board, Real time acquisition.

\author{
ABBREVIATION AND ACRONYMS \\ $i_{s 1}, i_{s 2}$ and $i_{s 3}$ : Three-phase stator currents; \\ $V_{s 1}, V_{s 2}$ and $V_{s 3}$ : Three-phase stator voltages; \\ $P h_{s 1}, P h_{s 2}$ and $P h_{s 3}$ : The stator phases; \\ $T_{m}$ : Electromagnetic torque; \\ $T_{L}$ : Load torque; \\ $\Omega$ : Rotation speed; \\ $\theta$ : Rotation angle; \\ $I_{s d}$ : Direct stator current; \\ $I_{s q}$ : Quadratic stator current; \\ GND: Ground; \\ [Pdqo]: PARK transformation; \\ $f_{a r}$ : Sampling frequency of the ARDUINO A/D \\ converter; \\ $f_{p c}$ : Transmission frequency of microcomputer; \\ $f_{\text {cap }}$ : Frequency of the captured signal; \\ $f_{a c q}:$ Sampling frequency; \\ COM14: Serial communication port $\left(\mathrm{N}^{\mathrm{o}} 14\right)$; \\ $u(1), u(2)$ and $u(3)$ : Signals captured on MATLAB; \\ $A_{0}, A_{1}$ and $A_{2}$ : The analog inputs of the Arduino \\ board; \\ $T_{\max }:$ MAX acquisition time.
}

\section{INTRODUCTION}

Diagnosis, in general, consists in identifying the nature and the cause of a failure from a philosophy of observation and redundancy. This is an important function for the safety and availability of the industrial systems [1].

Several studies have been carried out in the literature to develop robust diagnostic methods.
These methods are based on the different information available to describe the behavior of the systems. In most practical situations, the operating diagnostic is usually performed in the presence of measurement noise, disturbances, process noise and modeling errors [2, 3].

This paper presents the development of a diagnostic method which uses the measurement of motor currents in order to detect defects in electromechanical systems. It focuses on two main topics: the acquisition of experimental data, and the development of the diagnostic method.

Induction motors are most commonly used electrical machines in industry because of their cheep cost, small size, ruggedness, low maintenance cost, and easy operation with an available power supply. Although these induction motors are very reliable, but they are subjected to different types of faults and failures. These faults may be inherent to the machine itself or due to operating conditions $[3,4]$.

The original objective of this application is to reduce the cost of diagnosis compared to the cost of the physical system. The ARDUINO-Uno microcontroller is also used as a new process in real-time applications $\left(1^{\text {st }}\right.$ card was made from 2005). In this experimental work, we are interested in the diagnosis based on signal processing in real time, using the Park method for the detection of electrical (stator and rotor) or mechanical defects in an induction machine. To achieve this practical project, we use: the Arduino-Uno microcontroller 
card, the ACS720 current sensors and programming by MATLAB. The effectiveness of the MATLABArduino interface is presented to increase the realtime performances and robustness of the designed diagnostic systems.

\section{SYSTEM DESCRIPTION}

A typical diagnosis system shown in Figure 1 consists of a sensor assembly which provides the fault signal (generated by the test system) to a signal processing unit (acquisition unit), which further sends its result to be analyzed by expert systems (Microcomputer), where the corresponding fault is ultimately detected (by diagnostic algorithm) $[5,6,7,8]$.

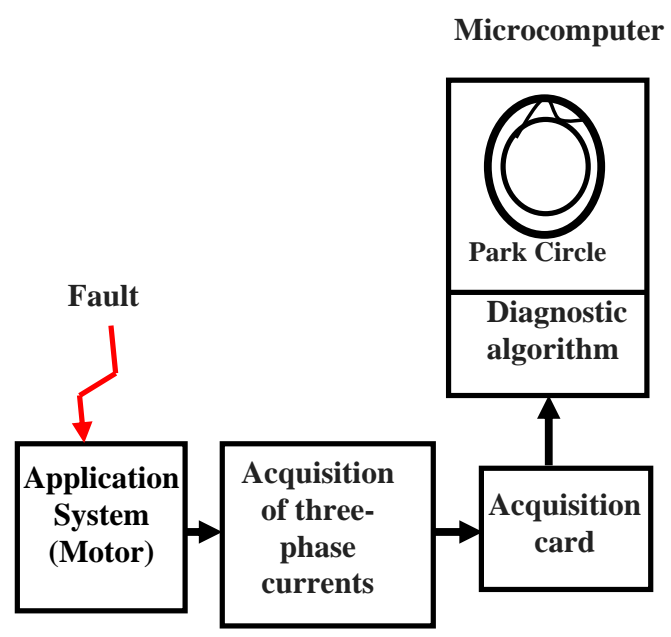

Fig. 1. Diagram of the diagnostic system

\section{STRUCTURE OF TEST SYSTEM}

The test system is an induction machine consisting of the stator and the rotor. The stator consists of three windings distributed in space and separated by an electrical angle of $120^{\circ}$, the same applies to the rotor whether it is a squirrel cage or formed of three short-circuit windings. This induction machine causes a mechanical load and is powered by a three-phase voltage source (see figure 2) $[9,10,11]$

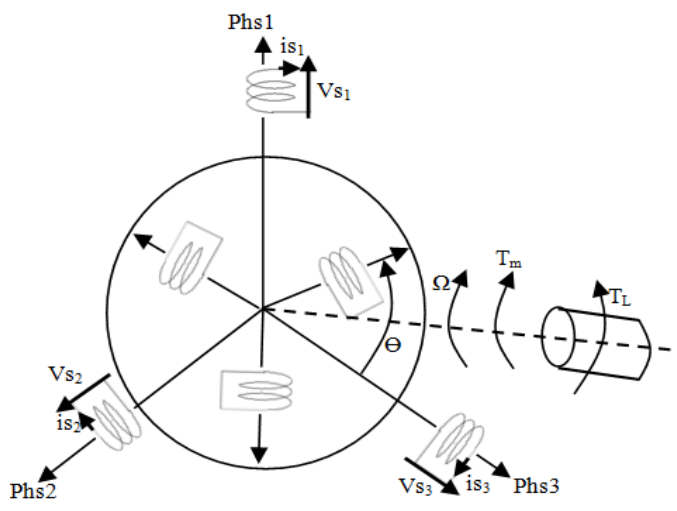

Fig. 2. System application (induction machine)
The fault can be shouted on the windings, the electric power source and the mechanical load.

\section{DIAGNOSTIC BY THE PARK METHOD}

This method is based on the Park transformation, through the transformation of a three-phase induction machine to a two-phase induction machine, along the two axes $\mathrm{d}$ and $\mathrm{q}$. From this transformation, we obtain the Park vectors of the tensions, fluxes and currents $[12,13]$. This technique uses the two components of the stator current isd and isq. As a function of mains phase variable $\left(i_{s l}, i_{s 2}, i_{s 3}\right)$, the Park's vector components $\left(I_{s d}, I_{s q}\right)$ are $[13,14]$ :

$\left[\begin{array}{l}I_{s d} \\ I_{s q} \\ I_{s o}\end{array}\right]=\left[P_{d q o}\left[\begin{array}{l}i_{s 1} \\ i_{s 2} \\ i_{s 3}\end{array}\right]\right.$

The Park transformation matrix is given by:

$\left[P_{d q o}\right]=\sqrt{\frac{2}{3}}\left[\begin{array}{ccc}\cos (\alpha) & \cos \left(\alpha-\frac{2 \pi}{3}\right) & \cos \left(\alpha-\frac{4 \pi}{3}\right) \\ -\sin (\alpha) & -\sin \left(\alpha-\frac{2 \pi}{3}\right) & -\sin \left(\frac{4 \pi}{3}\right) \\ \frac{1}{\sqrt{2}} & \frac{1}{\sqrt{2}} & \frac{1}{\sqrt{2}}\end{array}\right]$

$\alpha=\omega t$ being the angular displacement. By using the above transformation the orthogonal components of the Park's current vector can be computed from the symmetrical three-phased current system, having the components: $i_{s 1}, i_{s 2}$ and $i_{s 3}$ :

$$
\begin{aligned}
& I_{s d}=\sqrt{\frac{2}{3}}\left[i_{s 1} \cos (\alpha)+i_{s 2} \cos \left(\alpha-\frac{2 \pi}{3}\right)+i_{s 3} \cos \left(\alpha-\frac{4 \pi}{3}\right)\right. \\
& I_{s q}=\sqrt{\frac{2}{3}}\left[-i_{s 1} \sin (\alpha)-i_{s 2} \sin \left(\alpha-\frac{2 \pi}{3}\right)-i_{s 3} \sin \left(\alpha-\frac{4 \pi}{3}\right)\right.
\end{aligned}
$$

When the induction machine, if healthy, its three-phased stator current system is perfectly symmetric:

$$
\begin{aligned}
& i_{s 1}=\sqrt{2} I_{s} \sin (\alpha) \\
& i_{s 2}=\sqrt{2} I_{s} \sin \left(\alpha+\frac{2 \pi}{3}\right) \\
& i_{s 3}=\sqrt{2} I_{s} \sin \left(\alpha+\frac{4 \pi}{3}\right)
\end{aligned}
$$

If the reference is fixed in the stator of the machine the above equation becomes:

$$
\begin{aligned}
& i_{s d}=\sqrt{\frac{2}{3}} i_{s 1}-\frac{1}{\sqrt{6}} i_{s 2}-\frac{1}{\sqrt{6}} i_{s 3} \\
& i_{s q}=\frac{1}{\sqrt{2}} i_{s 2}-\frac{1}{\sqrt{2}} i_{s 3}
\end{aligned}
$$

In the case of the faultless motor, the curve $I_{s q}=$ $f\left(I_{s d}\right)$ has a circular shape centered at the origin $(0$, 0 ) and of diameter equal to the amplitude of the stator current corresponding to the operating state of the motor (as shown in Fig. 3). 


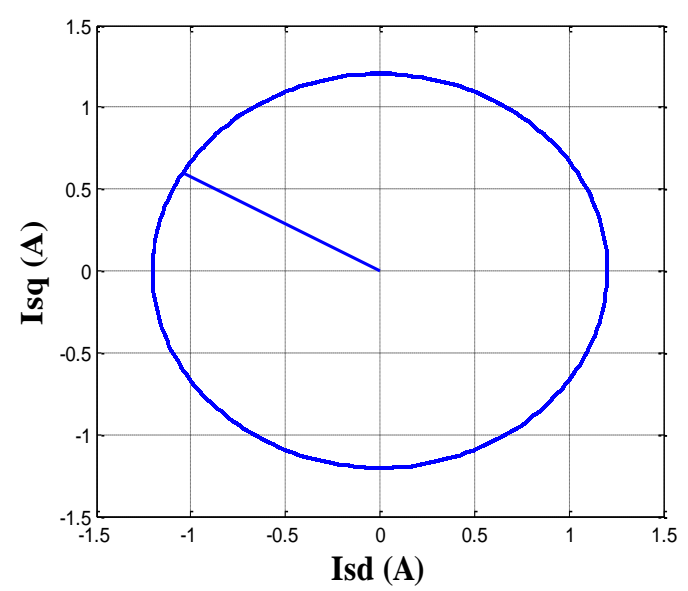

Fig. 3. Park circle without fault application

In the event of a fault on the induction motor, the circular curve changes in shape and thickness because of the presence of the harmonics created by the fault. The strategy of this method is to compare the two circular curves in the two cases of the motor with and without fault during its operation (as shown in Fig. 4).

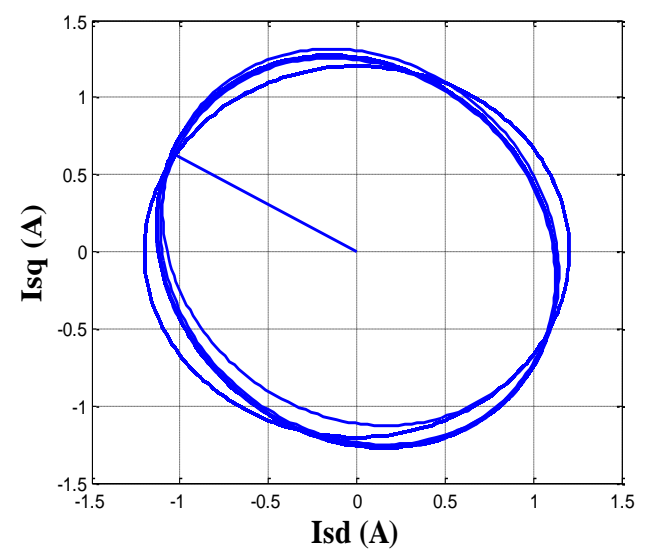

Fig. 4. Park circle with fault application

\section{DESCRIPTION OF THE PHYSICAL CIRCUIT}

Figure 5 shows the synoptic diagram of the studied diagnostic system (by the Park method). The power system consists of an induction machine, a load and a three-phase voltage source. In cascade, the diagnostic process is installed: the current sensors, the TG speed sensor, the ArduinoUNO board and the Arduino-MATLAB programming interface on the microcomputer.

Four types of defects are applied to the system: - a rotor connection fault (a bad contact),

- a stator connection fault (a bad contact),

- a voltage disturbance fault (a voltage drop),

- a mechanical disturbance fault (load variation).

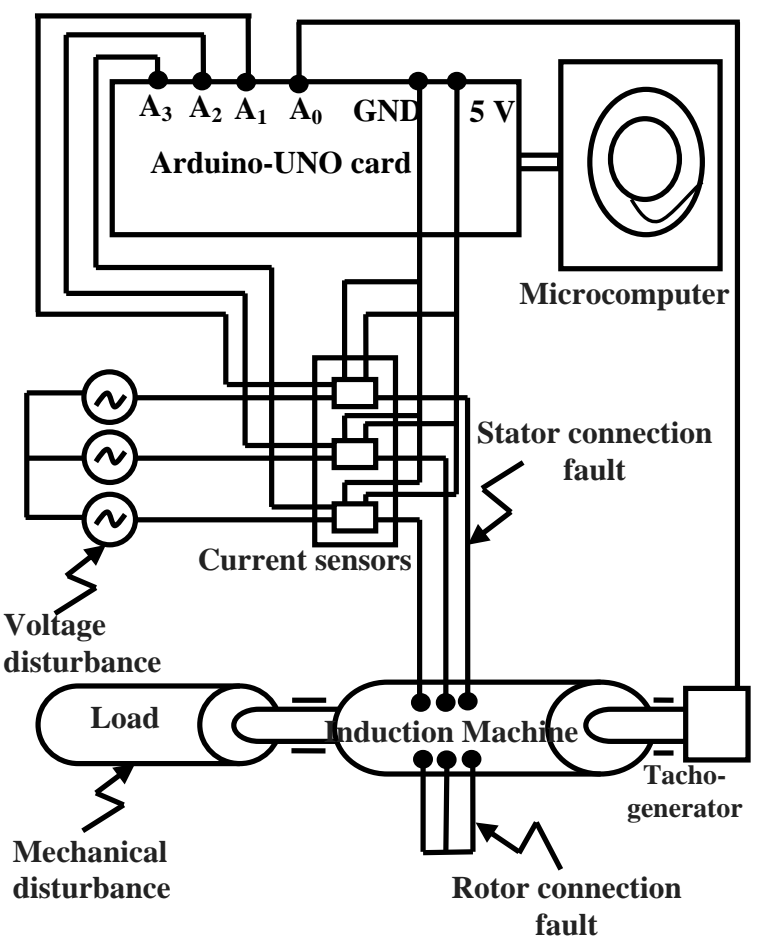

Fig. 5. Synoptic diagram of the studied diagnostic system

Images 6 and 7 illustrate successively the overall practical test bench and the detail of the acquisition system. The detail has been explained on the previous synoptic model (Fig. 5). The currents and speed are measured by current sensors (tachogenerator) and speed sensor, its outputs are interfaced with computer by Arduino-Uno microcontroller card and analyzed using MATLAB software.

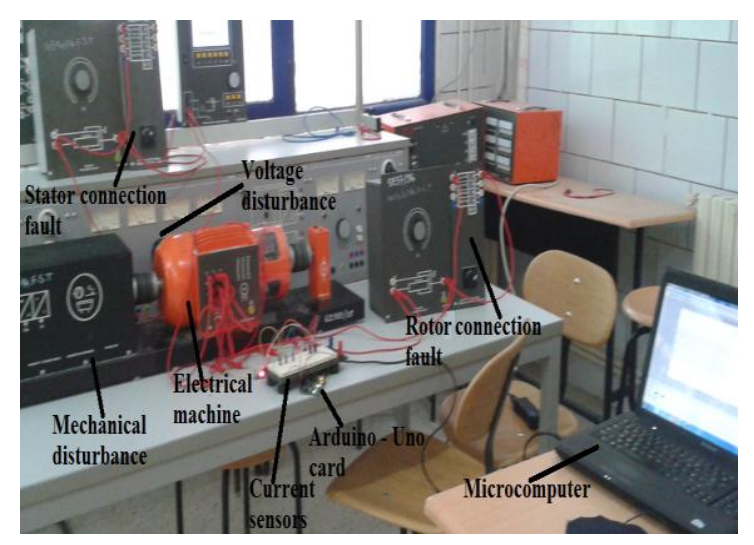

Fig. 6. Experimental setup

The three current sensors associated with the Arduino board are shown in figure 7. 


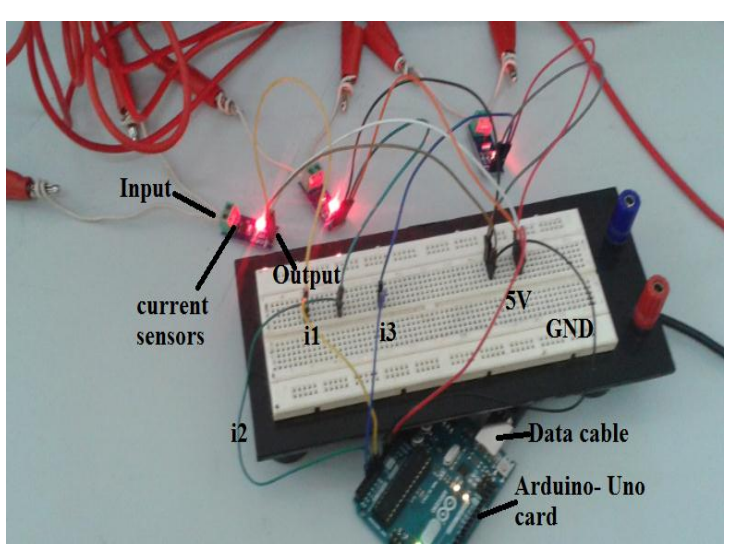

Fig. 7. Acquisition system

\section{REAL-TIME ANALYSIS}

The methodology contains the monitoring processes of different components of the induction motor. This system uses the Arduino-uno board for data acquisition. On acquisition chain, there are three tasks: measurement by sensor, acquisition by Arduino and real-time analysis on PC in interfacing with MATLAB software (Fig. 8). Through the bit capacity of the ARDUINO A/D converter (10 bits) and the max voltage (5Volts) of the analog inputs for the arduino board, a wide acquisition range from 0 to 1023 in hexadecimal is obtained.

Note, the acquisition frequency of the A/D converter $\left(f_{\text {acq }}\right)$ equals 100Kbps and sampling acquisition frequency $\left(\boldsymbol{f}_{\text {sacq }}\right)$ :

$f_{\text {sacq }}=(100000 / 10 / 50) f_{\text {cap }}=200 f_{\text {cap }}$ (For the four captured signals: $f_{\text {sacq }}=50 f_{\text {cap }}$ ).

The ARDUINO-PC transmission frequency $\left(f_{t r}\right)$ equals 38400bps (Or: 9600 bps, 57600bps), but the frequency of the captured signal $\left(f_{\text {cap }}\right)$ equals $50 \mathrm{~Hz}$. For every byte of data transmitted, there are actually 10 bits being sent: a start bit, 8 data bits, and a stop bit. So, at $\boldsymbol{f}_{\text {tr }}=38400 \mathrm{bps}$, we're actually sending 38400 bits per second or 3840 (38400/10) bytes per second and for $f_{t r}=9600 \mathrm{bps}$, we're actually sending 9600 bits per second or 960 (9600/10) bytes per second. By comparison, we obtain the sampling frequency $\left(\boldsymbol{f}_{s}\right)$ for $\boldsymbol{f}_{t r}=38400$ bps:

$\boldsymbol{f}_{s}=(38400 / 10 / 50 / 4) f_{\text {cap }} \approx 20 \boldsymbol{f}_{\text {cap }}$ (according to the theory of chanone in practice, as shown in Figure 9).

The current sensor generates a proportional voltage to the captured current (Fig. 10). It is necessary to eliminate the additive offset and the multiplicative offset to obtain correct measurements.

Figure 11 shows the sampling of a stator current phase (is1) after the acquisition by Arduino-Matlab interfacing on PC (in our application).

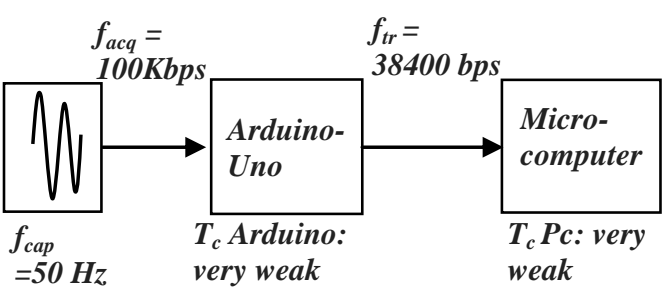

Fig. 8. The real time acquisition Chain

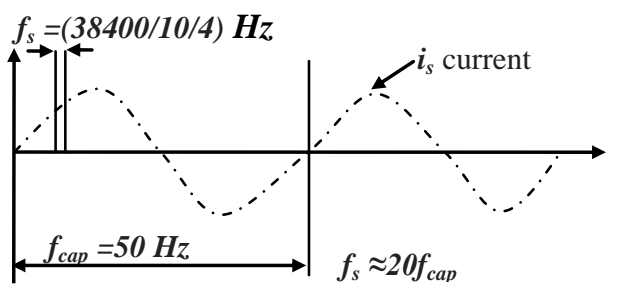

Fig. 9. Real-time analysis

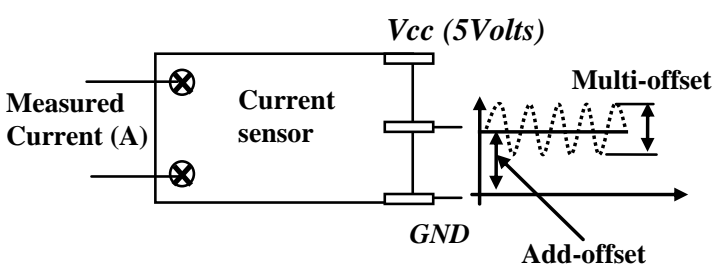

Fig. 10. Offset of the sensor

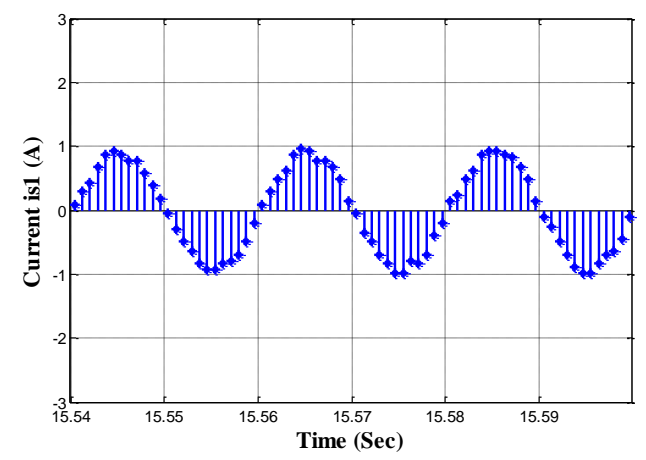

Fig. 11. Sampling of a stator current phase

\section{EXPERIMENTAL RESULTS}

\subsection{Without fault application}

Figures 12 and 13 show successively the three phase $i_{\text {s123 }}$ and the homogeneous Park circle of the stator currents absorbed by the induction machine without fault application. There is a slight width on the circle and small variations in $i_{\text {sabc }}$ current magnitudes due to degradation of the voltage quality generated by the power supply network. Then, there are harmonics generated by the electrical source. 


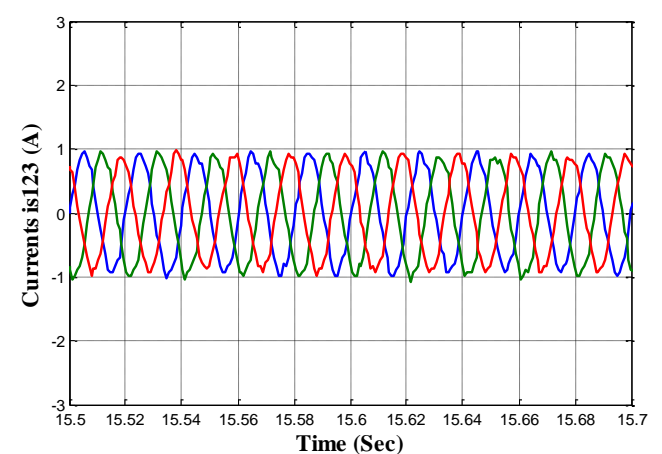

Fig. 12. Stator currents variation

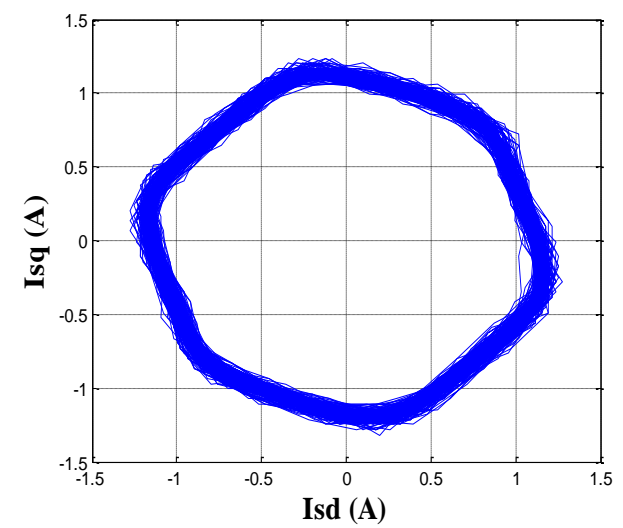

Fig. 13. Practical result of Park circle without fault application

\subsection{With fault application}

Figures 14 through 25 show the diagnostic performance by the Park method on the system under study. In this study, we used Real-Time digital acquisition and processing (Arduino-Matlab interfacing). The four types of defects are applied as previously mentioned.

\subsubsection{Rotor connection fault}

In figs. 14, 15 and 16, the diagnosis of a bad contact fault is obtained in a rotor phase of order $15 \Omega$ : Fluctuations in the speed and amplitude of the stator currents are observed after the instant application of the defect to (30s) and the deformation of the Park circle in increase of the width.

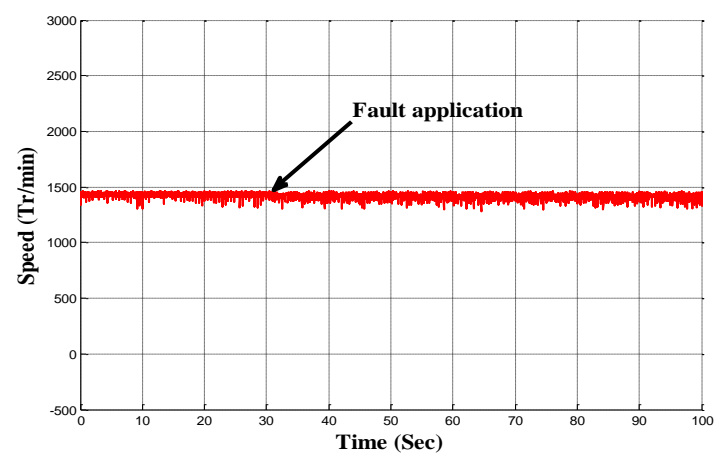

Fig. 14. Rotor speed variation

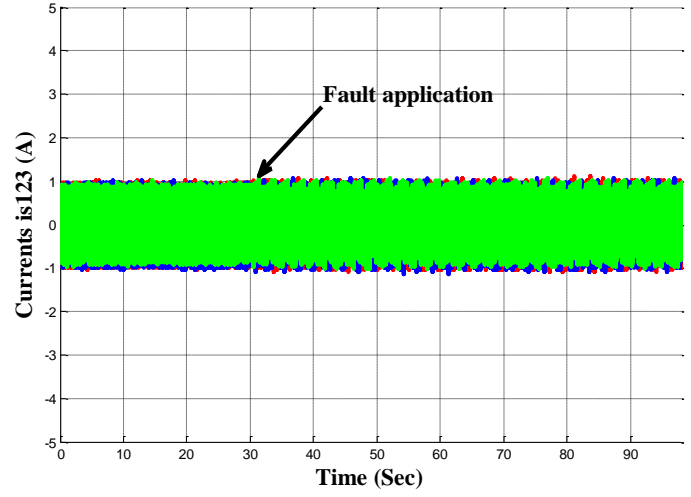

Fig. 15. Stator currents variation

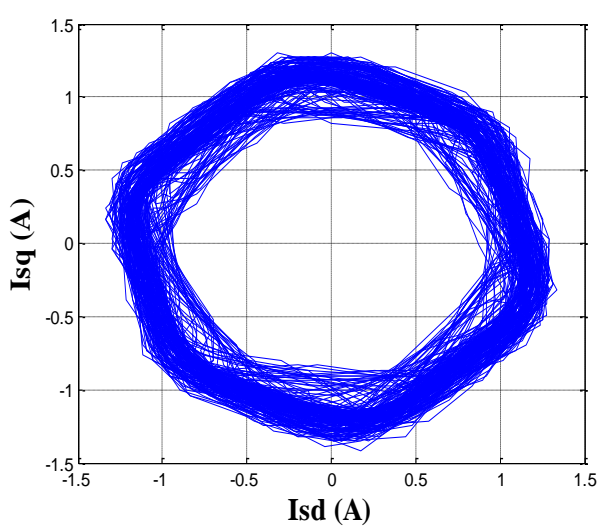

Fig. 16. Park circle deformation

\subsubsection{Stator connection fault}

The results of figures 17, 18 and 19 represent the dynamic and electrical behavior of the system during the appearance of a bad stator contact at $15 \Omega$. After the instant of the fault at $(30 \mathrm{~s})$, we notice: a negligible variation on the speed of rotation (Fig. 17), a considerable disequilibrium on the stator currents (Fig.18) with a deformation or opening of a Park circle (Fig. 19).

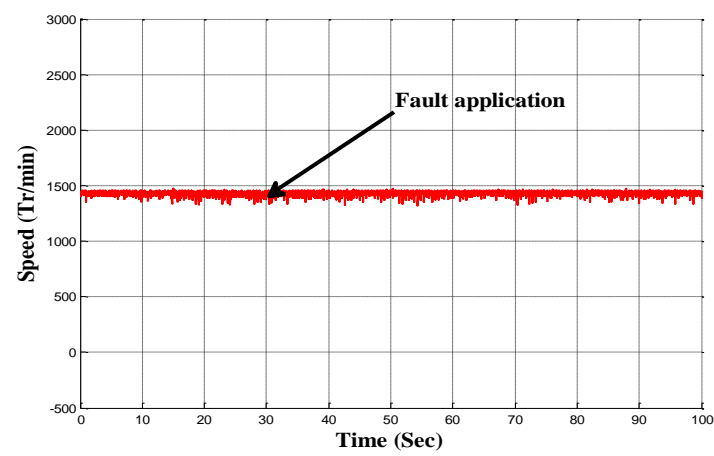

Fig. 17. Rotor speed variation

\subsubsection{Mechanical disturbance}

The disturbances of the mechanical load present on the system by the decrease of the speed and the increase of the stator currents (See figs. 20 and 21). Note also the fault signaling by the change of the state of equilibrium towards the outside in Park (Fig. 22). 


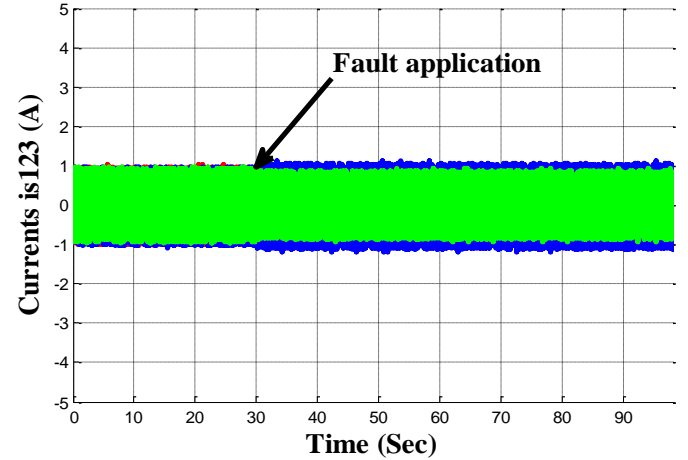

Fig. 18. Stator currents variation

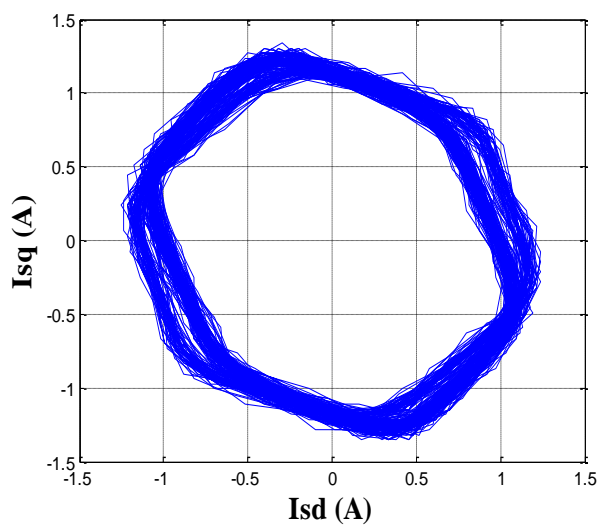

Fig. 19. Park circle deformation

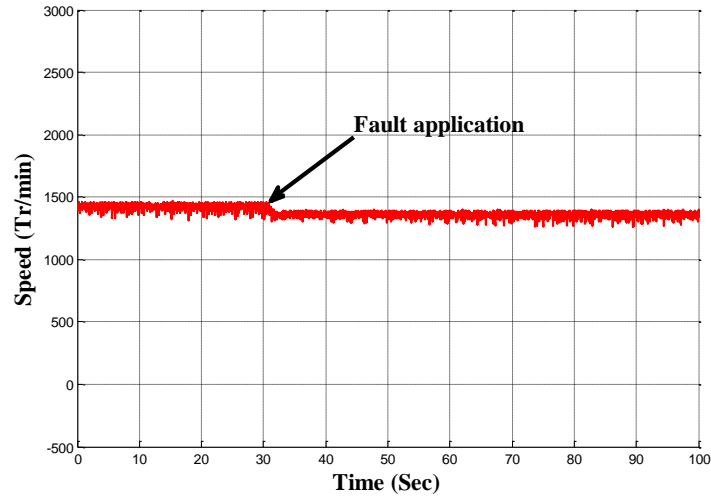

Fig. 20. Rotor speed variation

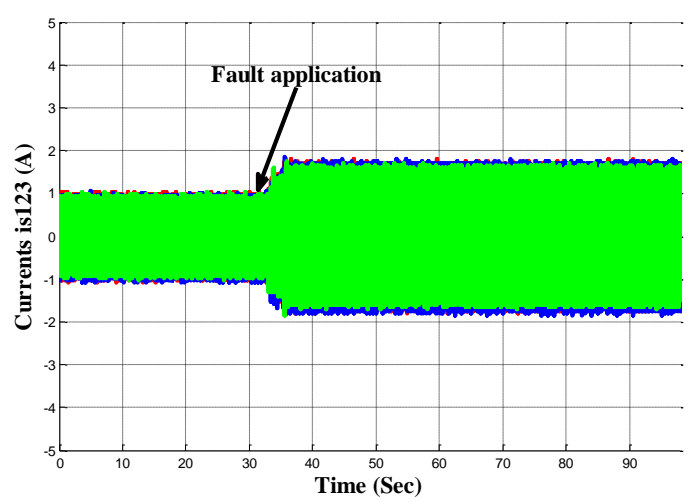

Fig. 21. Stator currents variation

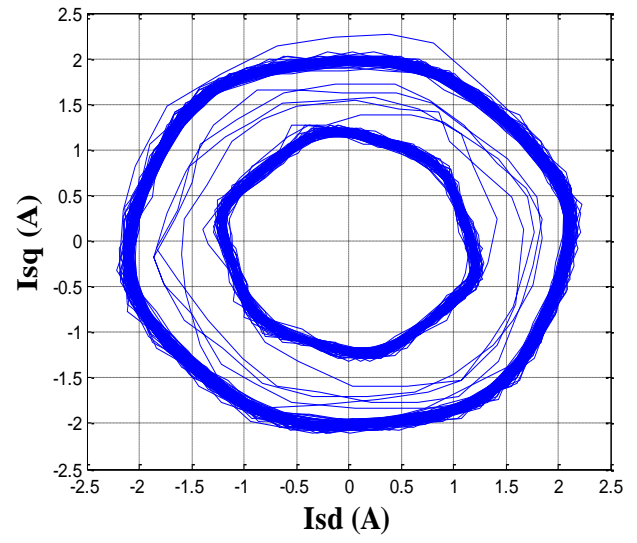

Fig. 22. Park circle deformation

\subsubsection{Voltage disturbance}

Figs. 23, 24 and 25 show the effect of the drop in the stator power supply voltage at $70 \%$. Such as the decrease of the speed and the stator current (see Figures 23 and 24). This type of defect is indicated by the change of steady state inside the Park circle (Figure 25).

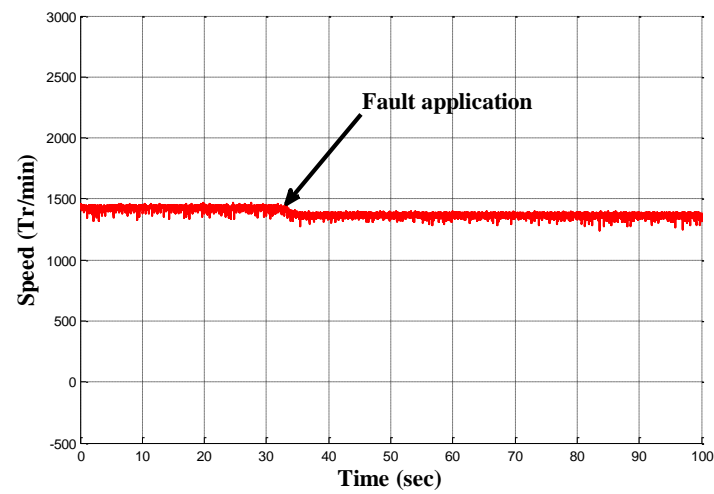

Fig. 23. Rotor speed variation

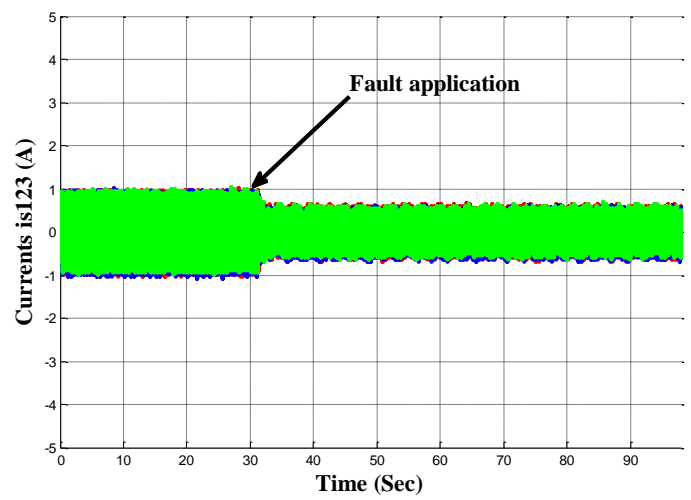

Fig. 24. Stator currents variation 


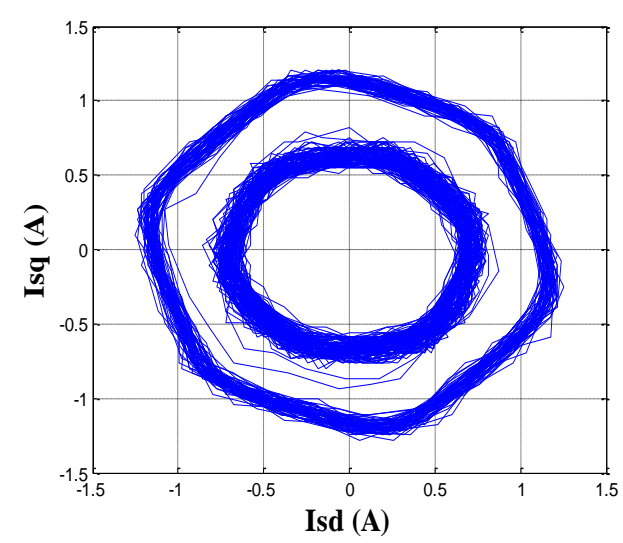

Fig. 25. Park circle deformation

\subsection{Quantitative description of results}

Using the fault signature of the PARK circle, there is a specific transient deformation for each type of fault. If there are identical cases, we can differentiate by two other signatures (rotational speed and stator electric currents), such that:

- On the signature of the circle of PARK: The deformation of the circle, the opening of the circle and change of equilibrium state (the variation of the diameter);

- On speed signature: signal distortion and change of equilibrium state;

- On the signature of the stator current: signal distortion, change of equilibrium state (the variation of the amplitude) and the disequilibrium of the phases.

\section{CONCLUSION}

This paper described about the stator currents signature analysis in induction motor by Park method. From the results of this work, it can be concluded that there is a specific Park circle structure for each type of faults. The latter is more sensitive to rotor faults than stator faults. Voltage defects and load disturbance can be separated by the steady state change path in Park and by the increase and decrease of the rotational speed. It can also be said that this diagnostic method is a very simple to implement, very powerful and very sensitive strategy for signaling and identifying the different types of faults. Examination of the results obtained with the combination of application processes (Arduino - sensors in Matlab interfacing) shows that the quality of signal acquisition performance ensures the desired goal. As a future perspective, the acoustic diagnosis of electrical machines will be proposed using the ARDUINOUno board.

\section{APPENDIX}

A) The acquisition program by Arduino:

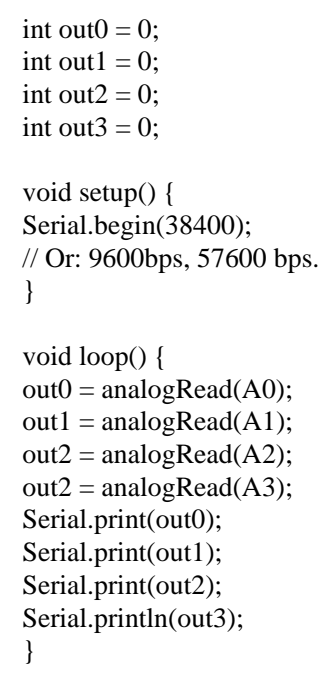

B) The diagram of acquisition and diagnosis on Matlab :

* Deleting the behavior of the serial port

(COM14)

* Creating serial objects (S) attached to the serial port (COM14)

* Opening the serial port

* Declaration of measurement parameters: $\boldsymbol{t}_{\max }$ and rate

* Preparation and declaration of the figure parameters

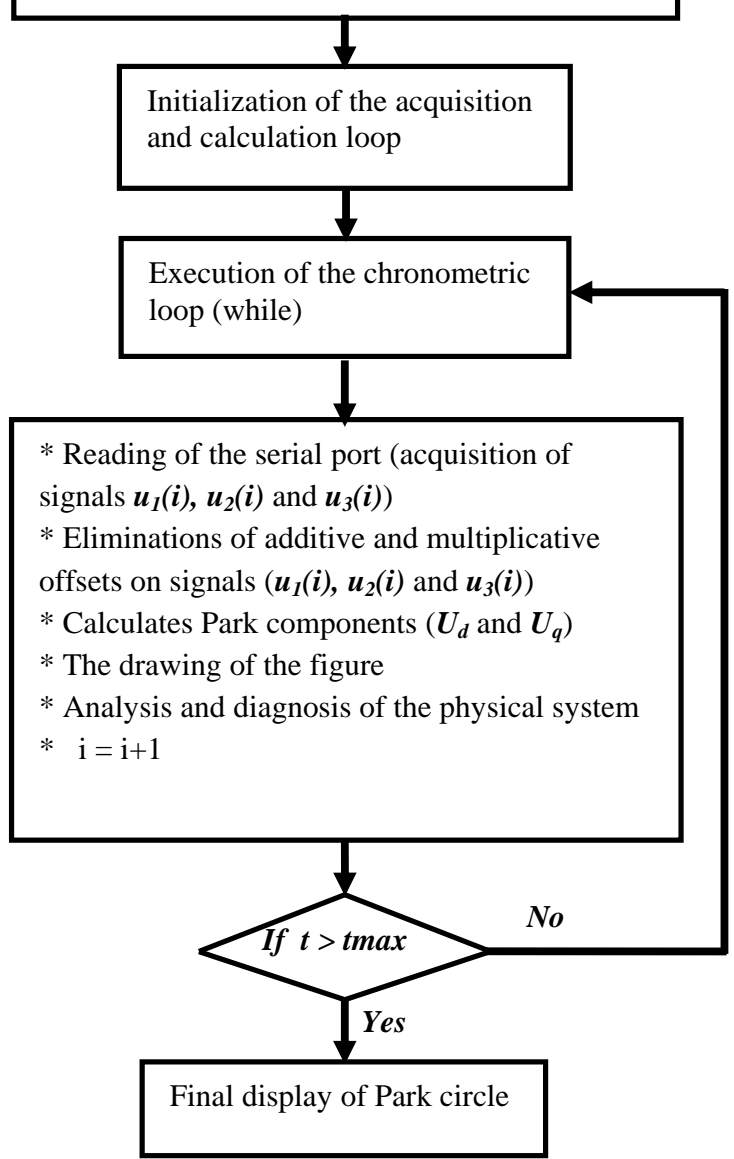




\section{C) The system data: \\ C.1) The data of the induction machine}

Machine type: Induction machine (coiled rotor); Nominal power $P n=1 K w$;

Frequency $\mathrm{fn}=50 \mathrm{~Hz}$;

Stator nominal voltage $V n=380 / 220$ Volts;

Stator nominal current $I n=3.2 / 5.3 A$;

Nominal speed $\mathrm{Nn}=1410 \mathrm{tour} / \mathrm{min}$.

\section{C.2) ACS-720 sensor data}

A positive or negative current measurement module based on the Allegro Microsystems chipset ACS720 $E L C-05 B$, the operation principle is based on the hall effect. Output voltage proportional to the measured current, $185 \mathrm{mV} / \mathrm{A}$. Physically isolated output of the input (well protected against defects). LED presence indicator VCC 5Volts (See figure below). The measuring range between $\boldsymbol{O A}$ to $\boldsymbol{i}_{\max } \mathbf{5} \mathbf{5 A}$. The additive measurement offset equal to 2.5 Volt (the signal has to be decreased by $-2.5 \mathrm{~V}$ ), and the multiplicative measurement offset equals $1 / 10$ (the signal has to be multiplied by 10 ).

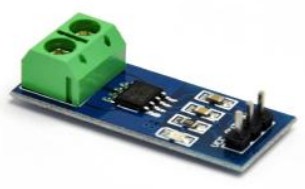

ACS-720 sensor

\section{C.3) The performance and technical} characteristics of the Arduino-Uno board

Microcontroller: ATmega328P;

Clock speed: $16 \mathrm{MHz}$;

Operating voltage: $5 \mathrm{~V}$;

Digital I / O Pins: 14;

Analog input pins: 6 ;

DC Current by I O Pin: $20 m A$;

DC current for $3.3 \mathrm{~V}$ Pin: $50 \mathrm{~mA}$;

Flash memory: $32 \mathrm{~KB}$ (ATmega328P);

SRAM: 2 KB (ATmega328P);

EEPROM: $1 \mathrm{~KB}$ (ATmega328P);

The accuracy of the measurement is 10 bits (The result is on 10 bits, between 0 and 1023);

The measurement takes about $100 \mu \mathrm{s}$, that's a maximum of 10,000 measurements per second.

\section{REFERENCES}

1. Anant G Kulkarni, Dr Manoj Jha, Dr M F Qureshi. Simulation of fault diagnosis of induction motor based on spectral analysis of stator current signal using fast fourier transform. IJISET-International Journal of Innovative Science, Engineering \& Technology 2014; 1 (4): 40-47.

2. El Sayed M Tag Eldin, Nivin Ghamry. A PIC microcontroller-based protection system of threephase induction motor. International Journal of Soft Computing 2016; 11 (3): 212-220.
3. Boltezar M, Slavic J. Fault detection of DC electric motors using the bispectral analysis. Meccanica Springer, 2006; 41: 283-297, https://doi.org/10.1007/s11012-005-5898-0

4. Shuang Pan, Tian Han, Andy C C Tan, Tian Ran Lin. Fault diagnosis system of induction motors based on multiscale entropy and support vector machine with mutual information algorithm. Hindawi Publishing Corporation, Shock and Vibration, 2016: 1-12. http://dx.doi.org/10.1155/2016/5836717

5. Chaitali S Kalaskar, Vitthal J Gond. Motor current signature analysis to detect the fault in induction motor. Journal of Engineering Research and Applications 2014; 4(6): 58-61.

6. Partha Sarathee Bhowmik, Sourav pradhan, mangal prakash. fault diagnostic and monitoring methods of induction motor: a review. International Journal of Applied Control, Electrical and Electronics Engineering (IJACEEE) 2013: 1(1): 1-18.

7. Khichada Bhavin A, K J Chudashma, Vyas Darshan M, Shiyal Jignesh D. 3-Phase induction motor parameter monitoring and analysis using Labview. International Journal of Electrical Engineering \& Technology (IJEET) 2016; 7(6): 81-91.

8. Pramod Sharma, Neelam Saraswat. Diagnosis of motor faults using sound signature analysis. International Journal of Innovative Research in Electrical, Electronics, Instrumentation and Control Engineering 2015; 3(5): 80-83. http://dx.doi.org/10.17148/IJIREEICE.2015.352

9. Yavuz Bahadır Koca, Abdurrahman Ünsal. A review on detection and monitoring of stator faults of induction motors. International Journal of Innovative Research in Science, Engineering and Technology (IJIRSET) 2017; 6(10).

10. Faeka M H Khater, Mohamed I Abu El-Sebah, Mohamed Osama, Khaled S Sakkoury. Proposed fault diagnostics of a broken rotor bar induction motor fed from PWM inverter. Journal of Electrical Systems and Information Technology, 2016; 3: 387397. https://doi.org/10.1016/j.jesit.2016.07.004

11. Mohammed Obaid Mustafa, George Nikolakopoulos, Thomas Gustafsson. A fault diagnosis scheme for three phase induction motors based on uncertainty bounds. CON 2012 - 38th Annual Conference on IEEE Industrial Electronics Society, 2012.

12. Shashidhara SM, Raju PS. Stator winding fault diagnosis of three-phase induction motor by park's vector approach. International Journal of Advanced Research in Electrical, Electronics and Instrumentation Engineering 2013; 2(7): 2901- 2906.

13. Turk N. Fault diagnosis using park's vector approach. International Journal of Electrical and Computer Engineering. 2016; 8(1): 7-11.

14. Young Jin Go, Myoung-Hyun Song, Jun-Young Kim, Buhm Lee, Wangrim Choi, Kyoung-Min Kim. A new algorithm of online stator faults diagnosis of threephase induction motors using duty ratios of halfperiod frequencies according to phase angle changes. MATEC Web of Conferences (ICMIT 2016): 1-6 https://doi.org/10.1051/matecconf/20167009002.

Received 2017-11-06

Accepted 2018-05-10

Available online 2018-05-22 


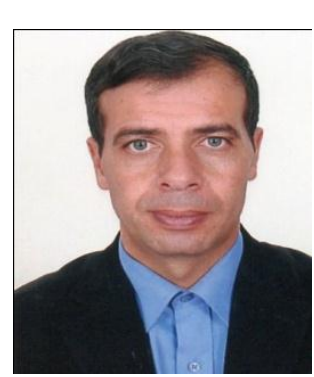

\section{Mohamed BOUDIAF}

received his Electrical

Engineering Diploma in 2004 and Magister degree in 2007

from the Electrical Engineering Institute of The Ibn Khaldoun University, Tiaret, Algeria. From 2009 to 2017, He joined at the Electrical Department, Ziane Achour University Djelfa. He received his Ph.D in June 2014 from the Electrical Engineering Department of The University of Sciences and Technology of Oran (USTO), Oran, Algeria. His research interests include power system analysis and FACTS devices.

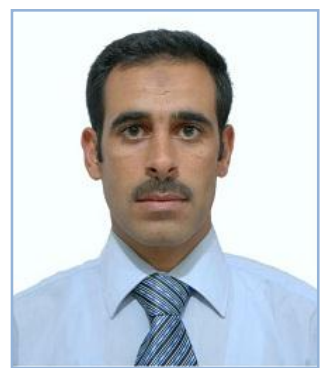

Lakhmissi CHERROUN received the state engineer degree in 2006, the magister in 2009 and the Phd degree in 2014, all in automatic and control from the department of automatic, university of Biskra-Algeria. He

currently an associate professor at electrical engineering department, university of Djelfa. His research interests include robotics, intelligent systems and diagnostics.

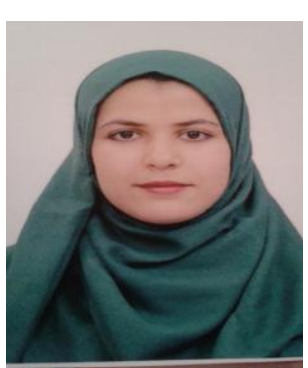

Maroua BENBRIKA received his licence Diploma in 2015 and Master degree in 2017, all in Maintenance in industrial instrumentation from the Electrical Engineering department of ZIANE Acheur University, Djelfa, Algeria. His research interests include systems diagnosis and realtime systems. 